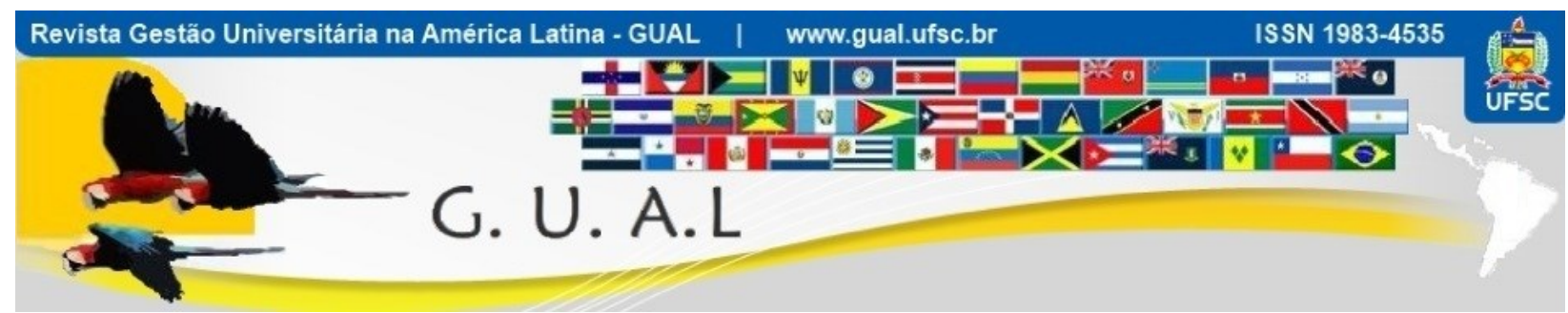

DOI: http://dx.doi.org/10.5007/1983-4535.2016v9n3p1

\title{
O COMPARTILHAMENTO DE DISCIPLINAS COMO MEIO PARA A SUSTENTABILIDADE FINANCEIRA DOS CURSOS E DAS INSTITUIÇÕES DE ENSINO SUPERIOR
}

\author{
SHARING COURSES AS A MEANS TO FINANCIAL SUSTAINABILITY OF \\ UNDERGRADUATE PROGRAMS AND HIGHER EDUCATION INSTITUTIONS
}

Carlos Cyrne, Doutor

Unidade Integrada Vale do Taquari de Ensino Superior - UNIVATES cyrne@,univates.br

Júlia Barden, Doutora Unidade Integrada Vale do Taquari de Ensino Superior - UNIVATES jbarden@univates.br

Marlene Sphor, Mestre Unidade Integrada Vale do Taquari de Ensino Superior - UNIVATES mspohr@univates.br

Luciana Fernandes, Mestre Unidade Integrada Vale do Taquari de Ensino Superior - UNIVATES lufernandes@univates.br

Mouriac Diemer, Mestre Unidade Integrada Vale do Taquari de Ensino Superior - UNIVATES mouriac@univates.br

Edi Fassini, Mestre Unidade Integrada Vale do Taquari de Ensino Superior - UNIVATES edif@,univates.br

Recebido em 03/junho/2014

Aprovado em 03/maio/2016

Sistema de Avaliação: Double Blind Review

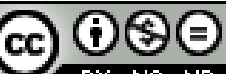

Esta obra está sob uma Licença Creative Commons Atribuição-Uso. 


\begin{abstract}
RESUMO
O presente texto traz o resultado de um esforço realizado para a implementação do compartilhamento de disciplinas entre os diferentes cursos de graduação da UNIVATES Centro Universitário, com a finalidade de contribuir para a sustentabilidade dos mesmos. Para que se pudesse atender ao objetivo realizou-se uma pesquisa qualitativa que se valeu de pesquisa bibliográfica, pesquisa documental e entrevista com diferentes atores envolvidos na oferta dos cursos de graduação bem como com os integrantes da área de contabilidade da instituição. Foram avaliados os diferentes projetos pedagógicos dos cursos buscando identificar as proximidades entre os mesmos que viabilizassem um maior compartilhamento de disciplinas. Após diversas etapas foi possível propor uma configuração que permitiu a implementação das disciplinas obrigatórias a todos os cursos, com a finalidade de imprimir nos egressos a marca da instituição; disciplinas obrigatórias comuns por área de conhecimento o que permitiu a elevação da margem de contribuição em quatro pontos percentuais, atendendo assim ao objetivo proposto para a pesquisa.
\end{abstract}

Palavras-chave: Sustentabilidade. Compartilhamento. Disciplinas.

\begin{abstract}
This paper presents the result of an effort to implement shared courses among several undergraduate Programs at UNIVATES - University Center, in order to contribute to their sustainability. In order to reach that goal a qualitative research was carried out, which encompassed literature review, documental review and interviews with the different actors involved in offering undergraduate programs as well as with staff of the Institution's accounting department. Pedagogical projects of the Programs were analyzed seeking to identify similarities among them which would ensure a greater possibility to share courses. After passing through several stages, it was possible to present a proposal that allowed the establishment of mandatory courses for all Programs, so that UNIVATES' graduates would carry its mark; and common compulsory courses within areas of knowledge enabled the rise of the contribution margin by four percentage points, thus meeting the proposed research goal.
\end{abstract}

Key words: Sustainability. Sharing. Courses. 


\section{INTRODUÇÃO}

A expansão do Centro Universitário Univates concretizou um sonho da região do Vale do Taquari/RS e arredores que buscavam a possibilidade de obter a formação no Ensino Superior na região, tendo à disposição opções de cursos que atendessem, além das necessidades do mundo do trabalho, o desejo dos jovens, candidatos a esse nível de ensino.

O universo de candidatos às vagas oferecidas é limitado, tendo em vista a localização de várias universidades num raio inferior a $150 \mathrm{~km}$, que disputam com a Univates os interessados em Formação Superior. Assim, desde o início da expansão, constata-se a diluição dos candidatos nos diversos cursos oferecidos.

Com base nesse contexto se discutiu a descontinuidade de cursos e se decidiu pela extinção de um ou outro, ou pela não oferta no processo seletivo vestibular, caso se tratasse de curso novo com baixa procura. Contudo, tem sido difícil e polêmica a decisão de suspender o processo seletivo, pois há uma série de variáveis envolvidas. De um lado, o desejo de ampliar a formação para várias áreas profissionais, uma necessidade para o desenvolvimento social, econômico e cultural equilibrado da região; de outro, a necessidade de compatibilizar o desejo de um leque diversificado de cursos como opção para a formação profissional com a sustentabilidade financeira da Instituição.

Para enfrentar possíveis "cenários" ameaçadores, trabalhou-se a ideia de compartilhamento de disciplinas na construção dos Projetos Pedagógicos dos Cursos. Hoje há cursos, principalmente os implantados mais recentemente, organizados na perspectiva de uma considerável carga horária de disciplinas compartilhadas. Isso é resultado de trabalho iniciado há mais de uma década, quando se verificou que algumas disciplinas de um curso eram ministradas também em outros cursos, com ementas idênticas, porém códigos diferentes. Por determinação da Pró-reitoria de Ensino - Proen, o Núcleo de Apoio Pedagógico - NAP, verificou todas as matrizes curriculares com a finalidade de identificar as sobreposições e possibilidades de compartilhamento. Naquele momento criou-se uma "grade de equivalências", que, após aprovada, foi implantada na forma de unificação de ementas e códigos.

Em 2012 o Centro Universitário UNIVATES, determinou que se desenvolvesse um trabalho com os seguintes objetivos: a) propor uma política de compartilhamentos de disciplinas na Univates; b) propor um módulo de disciplinas institucionais de Formação Geral; c) orientar os compartilhamentos nos cursos de Formação de Professores. 
Para fundamentar e orientar a política de compartilhamento de disciplinas na Univates, o texto apresenta considerações sobre o Panorama do Ensino Superior no Brasil, contemplando, entre outros aspectos, as políticas do Ministério da Educação - MEC relativas à expansão e ao acesso amplo ao Ensino Superior e às implicações dessa expansão nas Instituições de Ensino Superior (IES), privadas e comunitárias.

Ainda, na direção do primeiro objetivo, no segundo momento, a Univates no cenário do Ensino Superior no Brasil, tecem-se considerações sobre possíveis ameaças e oportunidades para a Univates no cenário descrito. Logo a seguir, em o Compartilhamento de Disciplinas: oportunidade para fazer frente a ameaças agregando um diferencial comparativo na formação acadêmica, com vistas também ao primeiro objetivo, faz-se, inicialmente, uma retrospectiva histórica do movimento em direção ao compartilhamento de disciplinas nos cursos e centros, enfocando os objetivos e os princípios que os nortearam; a aceitação e as resistências nos cursos; os resultados das discussões.

Em seguida são apresentados os "princípios" e as "diretrizes" do compartilhamento, com base no conteúdo expresso no Projeto Pedagógico Institucional - PPI, nos Projetos Pedagógicos dos Cursos - PPCs, nas orientações constantes nas Diretrizes Curriculares Nacionais para os cursos de graduação, aprovadas pela Câmara de Educação Superior - CES, no Conselho Nacional de Educação - CNE, e, mais especificamente, no perfil dos ingressantes e no perfil do egresso dos cursos; bem como nas orientações dos Conselhos Profissionais.

Posteriormente é apresentada a proposta de Disciplinas Institucionais de Formação Geral, atendendo ao segundo objetivo deste documento. Traça-se, primeiramente, um histórico dos debates relativos à implantação de disciplinas institucionais de Formação Geral, enfocando as dificuldades e as resistências à proposta e os resultados alcançados. Em seguida são pautadas as diretrizes que orientam tanto a definição, quanto a organização das ementas e da metodologia de trabalho das disciplinas institucionais de Formação Geral na Univates.

\section{ASPECTOS GERAIS}

A última década foi marcada por uma série de modificações no que diz respeito ao Ensino Superior em nosso País. Constatou-se intensa movimentação na direção de viabilizar o acesso - nem tanto a permanência. Foram apresentadas políticas que buscaram democratizar o acesso, tendo sido criadas novas Instituições de Ensino Superior, tanto particulares como públicas federais (a partir do Programa de Reestruturação e Expansão das Universidades 
Federais - Reuni); dos Institutos Federais de Educação - IFS; apontando para uma interiorização das instituições, de forma a oportunizar aos jovens o acesso ao ensino de terceiro grau. Houve ainda o fenômeno da oferta do ensino a distância, que se apresentou como nova oportunidade de expansão. No campo do financiamento, ações como o Programa Universidade para Todos - ProUni e, mais recentemente, o Programa de Financiamento Estudantil - Novo Fies, foram iniciativas colocadas em execução como forma de suportar essa expansão.

Outro elemento, que atinge diretamente as instituições comunitárias ou confessionais, há de ser considerado (pois sendo essas, por sua natureza constitutiva e por princípio, instituições que primam pela qualidade e que se comprometem com o desenvolvimento da região onde estão inseridas) é o crescimento das IES com modelos de gestão pautados na racionalidade do lucro e na oferta da "qualidade mínima" provoca e estimula reflexões sobre a gestão universitária. A presença desse novo modelo de gestão universitária tem possibilitado a "canibalização" entre as instituições de ensino, tendo os processos de aquisição e de fusão proliferado nos últimos anos. Esse fato não pode ser desprezado, pois o segmento comunitário é tido como um dos "alvos" desses novos grupos empresariais.

De acordo com Braga e Monteiro (2005), "acabou a fartura". Os autores apresentam considerações sobre o mercado da educação superior brasileira, que, entre os anos de 1997 e 2003, teve incremento no número de alunos ingressantes de $154 \%$ (cento e cinquenta e quatro por cento), com crescimento de $17 \%$ (dezessete por cento) ao ano. Parte desse crescimento deveu-se à expansão do alunado no ensino médio, mas percebe-se que "entramos em um período de significativa redução deste crescimento" (BRAGA; MONTEIRO, 2005, p. 20). Passados dez anos é possível avaliar que o reflexo desse fato foi sentido pelo ensino superior, que passa por uma desaceleração na demanda.

Ao observar, porém, os números do censo da educação superior no Brasil, percebe-se que ainda existe um bom contingente de jovens com a ambição de ingressar no ensino superior. No entanto, grande percentual desse contingente não tem condições financeiras de demandar esse serviço.

Para fazer frente a esses desafios é preciso gerir as Universidades de uma maneira cada vez mais profissional. Conforme Marques (2005, p. 17), "a tendência é que os gestores das IES sejam, antes de tudo, bons administradores", de forma a evitar a solução de continuidade de suas organizações, muito embora se saiba que a "profissionalização da gestão 
educacional ainda está em fase embrionária” (BRAGA; MONTEIRO, 2005, p. 21). É como afirma Almeida (2000, p. 62), "apesar de os dirigentes da universidade brasileira atual alardearem sua adequação aos ditames da modernidade e da sociedade do conhecimento, ainda não praticam o que ensinam nos cursos de gerência e administração [...]”"

Nesse cenário está inserido o Centro Universitário UNIVATES, tendo a possibilidade de explorar a condição de que a educação é fator-chave para a melhoria da condição de vida de seus alunos e da comunidade regional. Porém, não está imune a possíveis situações de dificuldades em virtude dos diversos fatores (queda da demanda, inadimplência, evasão, expansão de grandes IES, diminuição do valor das mensalidades,...) que vêm afetando as IES em todo o país.

Em sua história da Univates busca a "profissionalização" desde os meados da década de 80 , período no qual foi obrigada a reinventar-se ou poderia sofrer solução de continuidade. Os gestores da época criaram alternativas que viabilizaram o crescimento da instituição, tendo o alcance da condição de Centro Universitário sido a oportunidade que, aproveitada, possibilitou a expansão e posterior consolidação dessa importante Instituição de Ensino Superior.

A despeito do crescimento dos últimos anos, dificuldades ainda se fazem presentes. A maior delas parece ser manter, e melhorar, o desempenho alcançado e, dentro da atual conjuntura, a continuidade do crescimento. A condição apresentada pode colocar frente a uma possibilidade de crise, mas também de oportunidade. É preciso encontrar formas de ser diferente dos concorrentes, isto é, apresentar diferenciais comparativos e, por que não, buscar diferenciais competitivos.

A concretização desses diferenciais competitivos será decorrência de decisões estratégicas, contudo, também é preciso que se mantenha a atenção em questões de eficiência e eficácia operacional, passando o trabalho desenvolvido nesse sentido pela otimização das ofertas de disciplinas dos diferentes cursos da Univates.

\section{O COMPARTILHAMENTO DE DISCIPLINAS: OPORTUNIDADE PARA FAZER FRENTE A AMEAÇAS, AGREGANDO UM DIFERENCIAL COMPARATIVO NA FORMAÇÃO}

As ações de compartilhamento se tornaram mais intensas a partir da criação dos cursos de Engenharia, cujos projetos, iniciados em 1999, foram implantados a partir de 2000. Em 2003 foi institucionalizado o NAP, que passou a acompanhar, com o auxílio da Secretaria 
Geral, as ofertas de disciplinas nos diferentes cursos. Por determinação da Pró-reitoria de Ensino da época, o NAP conduziu um estudo com a finalidade de identificar a duplicidade de ofertas de disciplinas, em dias e turnos diferentes, com códigos e nomes diferentes, mas com ementas iguais ou semelhantes. Elaborou-se uma proposta de unificação dessas disciplinas, que, encaminhada ao Conselho Universitário - Consun foi aprovada e determinada a implantação. Trabalho semelhante ocorreu em 2004 e 2005.

Consequentemente, um número menor de disciplinas passou a ser ofertado, viabilizando que alunos de diferentes cursos estivessem ao mesmo tempo em um mesmo espaço, racionalizando o uso dos recursos da Univates. Uma vez que mudanças implicam ruptura de paradigmas, é evidente que houve resistências, foi preciso um esforço de articulação e, por vezes “pulso firme” da Reitoria para implantar o proposto.

Tomando os dias atuais, eis que novo movimento se faz novamente necessário. Com esse intuito realizou-se um estudo buscando identificar que alternativas possui a Univates para ampliar o compartilhamento de disciplinas entre os diferentes cursos a partir de 2010. Tal estudo levou em consideração legislações internas e externas, bem como discussão conduzida pelos Diretores dos quatro Centros que compõem a Univates, com os professores e a Proen. Apontou, também, para a proposta de oferta de disciplinas institucionais de formação geral a serem compartilhadas por todos ou por parte dos cursos da Instituição.

\section{DIRETRIZES PARA O COMPARTILHAMENTO DE DISCIPLINAS DE FORMAÇÃO GERAL NA UNIVATES}

O ponto de partida foi a definição do perfil do egresso desejado pela Univates. Nesse sentido apelou-se ao Projeto Pedagógico Institucional (2006), parte integrante do Plano de Desenvolvimento Institucional - PDI, que se encontra "depositado" no Ministério da Educação, como um compromisso da Instituição para com aquele órgão de governo.

Avaliando as questões legais, uma das constatações é que a formação do egresso deve ir além das habilidades e competências específicas da profissão. Isto é, recomenda-se uma formação "integral" que dê conta de formar mais do que um profissional, um cidadão. Tal afirmação pode ser referendada pela Lei de Diretrizes e Bases da Educação Nacional - Lei

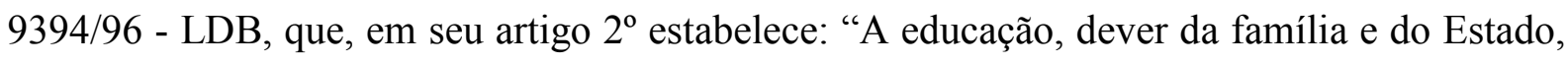
inspirada nos princípios de liberdade e nos ideais de solidariedade humana, tem por finalidade o pleno desenvolvimento do educando, seu preparo para o exercício da cidadania e sua qualificação para o trabalho". 
O artigo 55 do Estatuto do Centro Universitário UNIVATES preconiza que "os cursos de graduação da Univates têm em comum uma base de formação fundamental e humanística e preparo para a investigação científica e para a atuação no mundo do trabalho", tomando por base esse "mandamento" já se justifica o trabalho desenvolvido na busca de um conjunto de conteúdos de formação geral.

Durante algum tempo a formação no ensino superior fundamentava-se na concepção de currículos mínimos, o que implicava em detalhamento de disciplinas e cargas horárias, a serem obrigatoriamente cumpridas, podendo a falta de cumprimento levar a não autorização ou não reconhecimento de um curso. Essa condição inibia a inovação nos projetos pedagógicos. Felizmente, com o advento do Plano Nacional de Educação - PNE (2000) surgiu a proposta de elaboração de Diretrizes Curriculares Nacionais para os cursos. Na seção de objetivos e metas do referido plano, encontra-se: "Estabelecer, em nível nacional, diretrizes curriculares que assegurem a necessária flexibilidade e diversidade nos programas de estudos oferecidos pelas diferentes Instituições de Educação Superior, de forma a melhor atender às necessidades diferenciais de suas clientelas e às peculiaridades das regiões nas quais se inserem".

As Diretrizes foram elaboradas a partir de orientações emanadas do Conselho Nacional de Educação, que teve a incumbência de emitir pareceres que direcionassem a sua elaboração. Dentre os pareceres destacam-se dois: o Parecer 776/1997 e o 583/2001, que trouxeram as orientações para as diretrizes, podendo-se destacar o artigo $4^{\circ}$ do parecer 776 , que apresenta a necessidade de "incentivar uma sólida formação geral, necessária para que o futuro graduando possa vir a superar os desafios de renovadas condições do exercício profissional e de produção de conhecimento, permitindo variados tipos de formação e habilitações diferenciadas e um mesmo programa”. E o parecer 583/2001, que estabeleceu:

Visando a assegurar a flexibilidade e a qualidade da formação oferecida aos estudantes, as diretrizes curriculares devem observar os seguintes princípios: 1) Assegurar às Instituições de Ensino Superior ampla liberdade na composição da carga horária a ser cumprida para a integralização dos currículos, assim como na especificação das unidades de estudos a serem ministradas; [...]”.

Reforçando a ideia de uma sólida formação geral, o Fórum de Pró-Reitores de Graduação das universidades brasileiras - Forgrad, aponta que "a graduação, portanto, não deve voltar-se à perspectiva de uma profissionalização estrita e técnica, mas propiciar o 
desenvolvimento de competências de longo prazo e a construção de uma relação com o conhecimento que leve à efetiva leitura e ação crítica sobre seus fundamentos" (2004; p.12).

Retornando à LDB pode-se verificar no artigo $43^{\circ}$ e seus incisos II e VI que:

\begin{abstract}
A educação superior tem por finalidade: [...] II) formar diplomados nas diferentes áreas de conhecimento, aptos para a inserção em setores profissionais e para a participação no desenvolvimento da sociedade brasileira, e colaborar na sua formação contínua; [...] e VI) estimular o conhecimento dos problemas do mundo presente, em particular os nacionais e regionais, prestar serviços especializados à comunidade e estabelecer com esta uma relação de reciprocidade.
\end{abstract}

Da análise dos excertos legais acima, do descrito no PPI e da necessidade de ser eficientes e eficazes operacionalmente, chega-se à conclusão de que os cursos da Univates, sem retornar à condição de ter um currículo mínimo, precisam contemplar uma base de formação comum que seja capaz de dar suporte ao preconizado pela Lei e pelas diretrizes internas contemplando uma formação geral que oportunize ao egresso não apenas uma formação profissional técnica para atender a necessidades mais imediatas, mas uma formação que lhe dê condições de atuar de forma cidadã, de ter condições de vencer os desafios do mundo profissional, criando novas oportunidades, tendo presente que a graduação é uma formação inicial, devendo o aprofundamento dos conhecimentos ocorrer em nível de pósgraduação.

\title{
5 METODOLOGIA
}

A partir do exposto é possível apresentar o problema e os objetivos da pesquisa. A dúvida a ser respondida resumiu-se à: o compartilhamento de disciplinas pelos cursos de graduação da Univates contribui para incrementar a margem de contribuição e a sustentabilidade dos mesmos? Como objetivo principal teve-se: determinar se o compartilhamento de disciplinas pelos cursos de graduação da Univates contribui para incrementar a margem de contribuição e a sustentabilidade dos mesmos. Entre os objetivos específicos estavam: a) identificar em todos os cursos de graduação disciplinas com conteúdos semelhantes; b) avaliar se as disciplinas semelhantes atendiam ao proposto nos projetos pedagógicos dos cursos; c) propor a implantação de disciplinas de formação geral obrigatórias a todos os cursos; e) propor a implantação de disciplinas obrigatórias por área de conhecimento.

A pesquisa caracteriza-se, do ponto de vista da natureza, como aplicada e descritiva quanto aos seus fins; quanto aos métodos de abordagem é qualitativa, valendo-se de dados 
quantitativos; quanto aos meios utilizados pode-se dizer que é: bibliográfica, documental e de campo, pois foram manuseados dados secundários e primários; sendo, ainda, um estudo de caso.

\section{DIRETRIZES E PRINCÍPIOS NORTEADORES DA FORMAÇÃO GERAL NA UNIVATES}

A importância da formação geral se justifica na medida em que, conforme afirma Morin (2004, p. 72), “[...] o conhecimento técnico está reservado aos especialistas, cuja competência num domínio fechado se acompanha de uma incompetência, quando este domínio é parasitado por influências exteriores ou modificado por um acontecimento novo".

Não sendo suficiente somente atentar aos aspectos legais, realizou-se uma rápida incursão pelo estado da arte no que diz respeito ao processo de aprendizagem, buscando suportes para uma proposta para o ensino superior, particularmente, o desejado pela Univates.

$\mathrm{Na}$ busca da formação de um egresso que seja capaz de atender ao preconizado no PPI é necessário que se tenha um curso "integrando a formação técnica à humana e à ética, possibilitando ao educando a perspectiva de autonomia relativa ao trato com o conhecimento. A adequada articulação de uma forte formação humanística com os processos de desenvolvimento científico e tecnológico [...]" (Forgrad, 2004, p. 7). A política nacional de graduação proposta pelo Forgrad refere ainda que, "muito mais importante do que ensinar os conteúdos específicos, passa a ser ensinar como aprender, tarefa intrínseca a toda a investigação" (Forgrad, 2004, p. 8).

Na mesma direção Morin (2003, p. 18) afirma que "diante de situações mutáveis e incertas, os programas pouco valem e, em contrapartida, faz-se necessária à presença de um sujeito pensante e estrategista". Já Zabalza (2004, p. 49) diz que "parece que, hoje em dia, começa a predominar a ideia de que é preferível, inclusive do ponto de vista dos empregadores, que os indivíduos tenham formação geral suficientemente ampla e polivalente a ponto de permitir a mobilidade profissional”.

Fraunches (2008, p. 41) afirma que as Diretrizes Curriculares Nacionais - DCNs concebem a formação de nível superior como um processo contínuo, autônomo, com sólida formação básica e formação profissional fundamentada na competência teórico-prática, de acordo com o perfil de um formando adaptável às novas e emergentes demandas. Morin (2004, p. 16), citando Humboldt, afirma que a universidade não podia ter como vocação direta 
uma formação profissional que seria própria das escolas técnicas, mas uma vocação indireta responsável pela formação de uma atitude de investigação.

Das afirmações acima se pode depreender que a graduação deve ser embasada em uma formação geral e que a especialização pode dar-se pela educação continuada. A universidade desempenha um papel importante, mas não o encerra: a formação é iniciada antes de chegar à universidade, é desenvolvida tanto dentro como fora da sala de aula, continuando após ter alcançado o título correspondente por meio da formação permanente.

Considerando o mundo do trabalho, é preciso admitir que à necessidade de profissionais bem preparados, o que não se contempla somente com a formação inicial. Cresce, assim, a importância da formação continuada para dar conta das mutações advindas dos conhecimentos oriundos da academia. Como observa Mota (sd, p. 3): "o mundo extra educação tem se alterado com rapidez e profundidades absurdas, enquanto as metodologias educacionais adotadas têm se mantido essencialmente as mesmas". Esse autor coloca ainda a possibilidade de que, ao ingressar no mundo do trabalho, o profissional já esteja defasado. Isso posto se pode inferir que a formação hiperespecializada não encontra espaço nos dias de hoje, sendo mais importante um profissional egresso que como aponta Morin (2003, p. 18) seja 'um sujeito capaz de aprender, inventar e criar 'em' e 'durante' o seu caminho; pois 'saber pensar' é condição essencial de qualquer processo adequado de profissionalização: não se dispensa domínio de conteúdos, mas insiste-se em saber pensar, para dar conta de conteúdos novos e manter-se profissional inovador" (Demo, 2004, p. 69).

Sendo assim, as discussões indicam para a possibilidade de integrar os cursos da Univates em três blocos de disciplinas. O primeiro compreende um conjunto de disciplinas que deem conta da formação geral, que seriam responsáveis por "imprimir" a marca Univates em seus egressos. Essas disciplinas devem atender ao propósito de "formar" o egresso para pensar, a fim de "formar cidadãos capazes de enfrentar os problemas de seu tempo" (Morin, 2004, p. 26), para ler o mundo.

O segundo bloco, denominado de disciplinas comuns por Centro, devem conseguir caracterizar a área de formação do egresso (saúde, gestão, humanas e jurídicas, exatas) com a finalidade de possibilitar uma formação interdisciplinar, aproximando os alunos de saberes que permitam sua intervenção no mundo do trabalho em conjunto com os demais profissionais de sua área. Para tanto, cada Centro, sob a coordenação de seu Diretor, deve estabelecer o compartilhamento entre as áreas, atendendo a essa diretriz. 
O terceiro bloco compreende as especificidades de cada um dos cursos, em que os coordenadores devem sem perder de vista a necessidade de um profissional como o descrito nos documentos já referidos, atender aos aspectos que conferem identidade ao curso.

\subsection{PROPOSTA DE DISCIPLINAS DE FORMAÇÃO GERAL NA UNIVATES}

Embora as discussões sobre quais disciplinas devem compor cada um dos diferentes blocos, bem como as respectivas ementas e carga horária sempre estivessem pautadas nas diretrizes já mencionadas, as particularidades de cada um dos cursos e um certo corporativismo levam para soluções distintas. $\mathrm{O}$ grupo, então, resolveu apresentar a proposta à Reitoria, de forma que essa pudesse mediar o processo.

As disciplinas propostas foram: a) formação geral - comum a todos os cursos da Univates: Leitura e Produção de Texto; Temas Contemporâneos; Raciocínio Lógico e Matemático; Filosofia e Ética; todas com 60 (sessenta) horas; b) formação por Centro comuns aos cursos de cada um dos Centros: Antropologia; Sociologia; Metodologia da Pesquisa; Psicologia e Empreendedorismo. Essas disciplinas ocorrem em todos os Centros, porém direcionadas para as suas particularidades.

Foi proposta ainda a possibilidade de uma disciplina intercentros - Estatística, que poderia ser oferecida como Fundamentos de Estatística no Centro de Gestão Organizacional CGO e no Centro de Ciências Humanas e Jurídicas - CCHJ, como Probabilidade Estatística no Centro de Ciências Exatas e Tecnológicas - CETEC e Bioestatística no Centro de Ciências Biológicas e da Saúde - CCBS.

Após reunião com a Reitoria, buscou-se, em nova rodada de negociações, avaliar o impacto das propostas em cada um dos cursos. Para tanto, os diretores de Centro avaliaram, em conjunto ou não com seus coordenadores, as propostas e verificaram a necessidade de ampliação ou não de carga horária dos cursos, bem como a necessidade de substituição de alguma disciplina de forma a não acrescer horas no currículo.

Os diretores apresentaram um estudo que demonstrou o compartilhamento de disciplinas entre os cursos de graduação, considerando o que se dá entre três ou mais cursos. O que se pode constatar é que a cultura do compartilhamento já está presente na Univates, porém direcionada ou para as especificidades dos cursos (como entre as engenharias) ou para as questões comuns às grandes áreas (como saúde, licenciaturas), não existindo um conjunto 
de componentes curriculares que permita, de forma comum, a "impressão de uma marca Univates" em nossos alunos.

O documento elaborado pelos Diretores indica para percentuais de compartilhamento que vão desde 19\% (dezenove por cento) até 92\% (noventa e dois por cento) da carga horária de compartilhamento com outros cursos. Observa-se que há uma amplitude significativa demonstrando que há necessidade de atenção por parte da Univates para esse tema. Hora temos cursos "híbridos" ao extremo, hora temos cursos "puros" ao extremo. É claro que não se pode deixar de considerar as Diretrizes Curriculares Nacionais e também orientações dos conselhos profissionais. Mas o que também é certo é que existe espaço para melhorias.

Tabela 1 Percentuais de compartilhamento por curso na Univates - 2012.

\begin{tabular}{|c|c|}
\hline Centro de Ciências Exatas e Tecnológicas & \% compartilhamento \\
\hline Arquitetura e Urbanismo & 19,4 \\
\hline Sistemas de Informação & 78,6 \\
\hline Engenharia da Computação & 84,6 \\
\hline Engenharia de Produção & 72,5 \\
\hline Engenharia de Controle e Automação & 57,7 \\
\hline Engenharia Mecânica & 51,9 \\
\hline Engenharia Ambiental & 71,4 \\
\hline Engenharia de Alimentos & 74,5 \\
\hline Engenharia Civil & 64,5 \\
\hline Ciências Exatas & 45,2 \\
\hline Design Gráfico & 78,9 \\
\hline Design de Produtos & 92,1 \\
\hline Química Industrial & 35,7 \\
\hline Média do centro & 63,6 \\
\hline Centro de Ciências Biológicas e da Saúde & \% compartilhamento \\
\hline Biomedicina & 65,3 \\
\hline Ciências Biológicas - Licenciatura & 43,6 \\
\hline Enfermagem & 36,8 \\
\hline Farmácia & 55,8 \\
\hline Fisioterapia & 22,1 \\
\hline Nutrição & 36,8 \\
\hline Psicologia & 6,1 \\
\hline Superior de Tecnologia em Estética e cosmética & 27,8 \\
\hline Média do centro & 36,8 \\
\hline Centro de Ciências Humanas e Jurídicas & \% compartilhamento \\
\hline Direito & 11,6 \\
\hline Educação Física - Bacharelado & 70,7 \\
\hline Educação Física - Licenciatura & 83,2 \\
\hline História & 20,0 \\
\hline Jornalismo & 47,3 \\
\hline$\underline{\text { Letras - Português }}$ & 93,9 \\
\hline Letras - Línguas & 75,6 \\
\hline Pedagogia & 18,8 \\
\hline
\end{tabular}




\begin{tabular}{l|c}
\hline Publicidade e Propaganda & 54,8 \\
\hline Relações Públicas $\quad$ Centro de Gestão Organizacional & 61,2 \\
\hline Média do centro & 53,7 \\
\hline Administração & \% compartilhamento \\
\hline Administração -LFE Análise & 57,9 \\
\hline Administração - LFE Comex & 57,9 \\
\hline Administração - LFE Agro & 57,9 \\
\hline Administração - LFE Gestão em Turismo & 57,9 \\
\hline Administração - LFE Gestão de Cooperativas & 57,9 \\
\hline Ciências Contábeis & 57,9 \\
\hline Gestão de Micro e Pequenas Empresas & 14,3 \\
\hline Tecnologia em Logística & 87,0 \\
\hline Relações Internacionais & 64,5 \\
\hline Gestão de Cooperativas & 59,3 \\
\hline Média do centro & 25,0 \\
\hline
\end{tabular}

Fonte: banco de dados institucionais.

As possibilidades que foram discutidas, à exaustão, entre os diretores e a Proen, apresentadas, levam na direção da inclusão das disciplinas em substituição às horas destinadas às "Atividades Complementares" que passariam a figurar, além da carga horária atual dos cursos, em alguns casos, a supressão de alguma disciplina específica.

O resultado foi diverso entre os cursos, ocorrendo situações em que a modificação em relação às atividades complementares foi o suficiente até cursos nos quais se teria, adotando a proposta integralmente, desde um acréscimo de zero hora como em cursos do CGO, Administração, por exemplo, até um acréscimo de 420 (quatrocentas e vinte) horas, em cursos do CCBS, como Estética e Cosmética.

De posse desses dados os Diretores, a partir das discussões com seus Coordenadores, verbalizaram as dificuldades de aceitação que estavam encontrando. Em reunião com a Proen decidiu-se por levar a questão para mediação da Reitoria mais uma vez.

Em reunião realizada com a Reitoria cada um dos diretores manifestou posição, em nome próprio e de seus representados. O que predominou nas discussões foi à dificuldade que os cursos têm de aceitar a necessidade de uma formação mais geral e menos específica, muito embora a argumentação dos diretores apontando para tal necessidade. Em determinado momento da reunião foi manifestado que coordenadores admitem que, "se for necessário retirar disciplinas específicas, se retira, mas a contragosto". 
6.2 PROPOSTA ACORDADA DE DISCIPLINAS DE FORMAÇÃO GERAL NA UNIVATES

Apesar dos impasses e de, em alguns momentos, interesses corporativos se sobreporem, os encaminhamentos acerca da definição das disciplinas e respectivas ementas foram e continuarão sendo fundamentados, conforme já ressaltado no início deste documento, no que está expresso no PPI; nos PPCs; nas orientações constantes nas diretrizes curriculares para os cursos de graduação, aprovadas pela Câmara de Educação Superior - CES, no Conselho Nacional de Educação - CNE; nas habilidades e competências exigidas no Enade e, mais especificamente, no perfil dos ingressantes e dos egressos da Univates, bem como no perfil do egresso de cada curso. Também se considerou a orientação de não ampliar para além do mínimo a carga horária de cada curso; as exigências dos Conselhos Profissionais; as orientações do documento final da Conaes (2010) que servirá de base para o novo PNE 20112020 .

Importante ressaltar que se propõe que tanto as disciplinas quanto as ementas, a bibliografia e a metodologia a ser adotada em cada uma das disciplinas devem ser constantemente rediscutidas tanto entre os pares das áreas envolvidas, como também e, principalmente, com os Centros e com os diferentes conselhos dos Cursos, com o objetivo de avaliar as orientações das próprias diretrizes, bem como se os objetivos emanados dessas diretrizes estão sendo contemplados.

Fica evidente que a proposta de compartilhamento com base na oferta de disciplinas institucionais, no compartilhamento de disciplinas por áreas afins ultrapassa o objetivo inicial da viabilização econômica e procura, acima de tudo, agregar um diferencial na formação dos acadêmicos da Univates.

Tendo em vista os impasses, a Reitoria, a partir dos argumentos, arbitrou que, em vez da proposta integral, os cursos da Univates deverão conter em seus projetos pedagógicos, obrigatoriamente, as seguintes disciplinas de formação geral, todas com 60 (sessenta) horas: Leitura e Produção de Texto I; Temas Contemporâneos; e Filosofia e Ética.

Devendo ainda contar com pelo menos 120 (cento e vinte) horas de disciplinas entre as que se seguem: Psicologia Geral; Sociologia e Antropologia; Empreendedorismo; Raciocínio Lógico; Metodologia da Pesquisa; e Leitura e Produção de Texto II. 


\subsection{AVALIAÇÃO DO IMPACTO FINANCEIRO}

A opção pelas disciplinas acima elencadas é resultado das discussões realizadas, bem como, das orientações emanadas dos diferentes documentos consultados. Tem-se ciência de que elas não darão conta de todos os anseios, mas constituem o que foi possível acordar. A construção de uma justificativa de por que optar por uma disciplina e não por outra é difícil. Na verdade, o grupo buscou encontrar "conteúdos" que permitissem atender à formação geral. É importante destacar que esse conjunto de disciplinas não precisa constituir-se em definitiva, podendo ser alterada em momentos futuros a partir de novas dinâmicas apresentadas pelo ambiente no qual a universidade está inserida.

O Ementário proposto foi elaborado por integrantes dos diferentes Centros da Univates, permitindo assim uma participação da comunidade docente, dando continuidade a um processo conduzido, de forma participativa, pelos diretores de Centro. Abaixo seguem alguns argumentos para as disciplinas consideradas obrigatórias a todos os cursos. Para as demais, a justificativa acredita-se esteja no corpo do trabalho como um todo.

Há aspectos a serem considerados como justificativa para a opção por Leitura e Produção de Texto como uma das disciplinas institucionais obrigatórias para todos os cursos da Instituição. Em primeiro lugar, nos últimos 50 anos, e, mais intensamente, na última década, com perspectivas de estender-se por mais alguns anos, houve uma intensa revolução na área da comunicação, em consequência do avanço nas tecnologias de informação, com implicações profundas no uso e funcionamento da linguagem, mais especificamente, nos modos de ler e de expressar-se oralmente e por escrito. Preconiza-se a dita "Era da Informação e da Comunicação" o que exige aperfeiçoamento constante nesta área para fazer frente aos desafios que se impõem.

Em segundo lugar, ainda que o Ensino Básico busque uma formação condizente com os desafios da Era da Informação e da Comunicação, um considerável número de ingressantes no Ensino Superior apresenta deficiências em habilidades de leitura, de escrita e de manejo de recursos linguísticos, habilidades essas que são fundamentais no processo de aprendizagem. Em outras palavras, a grande maioria dos ingressantes ao Ensino Superior necessita trabalhar habilidades relacionadas à leitura (compreensão e interpretação), à escrita e ao manejo da língua, como: a) diferenciar ideias essenciais e secundárias; teses e argumentos; b) analisar situações-problema; c) diferenciar fato e opinião; d) posicionar-se em relação aos fatos e desenvolver argumentos; e) construir hipóteses; f) detectar contradições; g) detectar implícitos 
e pressupostos; h) extrair conclusões e fazer inferências por dedução; i) ler e produzir textos de diferentes gêneros; j) diferenciar os diferentes níveis de linguagem e o uso adequado à situação de comunicação; 1) estabelecer um diálogo entre diferentes textos, teorias, posições; m) detectar os conhecimentos prévios necessários para a compreensão e interpretação do texto e a produção dos sentidos. Essas habilidades, além de qualificarem o processo de aprendizagem, também contribuem para o sucesso dos acadêmicos em avaliações e provas, de modo especial, na do Enade.

Já em relação à disciplina de Temas Contemporâneos, a definição desta disciplina como uma das três institucionais obrigatórias para todos os cursos leva em consideração aspectos como: a) os temas abrangidos pelas questões de Forma Geral nas provas do Enade, entre os quais: sociodiversidade; relações de trabalho; redes sociais; problemáticas contemporâneas; multiculturalismo; globalização; cidadania; políticas públicas: educação, saúde e segurança; inclusão/exclusão social e digital. b) Também se considerou o descrito no perfil do egresso da Univates, entendendo que a disciplina deve contribuir para fundamentar a compreensão do cenário globalizado; questões sócio-históricas no processo de formação das sociedades modernas e contemporâneas, enfocando temas como: meio-ambiente, manifestações culturais e sua diversidade, movimentos sociais e étnicos, questões de gênero e políticas públicas no contexto regional, nacional e mundial, tendo em vista a formação de um profissional que, além de competência técnica, saiba entender a si e ao outro como cidadãos.

A disciplina de Filosofia e Ética integra o grupo das obrigatórias para todos os cursos da Univates para dar conta de parte do perfil dos egressos da Instituição, dos quais se espera que "assumam o compromisso de pautar-se por princípios da ética democrática e dignidade para atuação como profissional competente e como cidadão consciente da qualidade e das implicações éticas de sua atuação e intervenção profissional." Também está explicitado na missão da Univates o compromisso de gerar, mediar e difundir, além do conhecimento técnico, o humanístico. Há de se considerar também as diretrizes do MEC para os cursos de graduação das IES brasileiras, que explicitam como conteúdos básicos e/ou de formação básica, disciplinas na área de humanidades: Filosofia, História, Sociologia, Antropologia, Ciência Política.

É possível que surjam questionamentos inquietantes: a) cinco disciplinas, 300 horas, três obrigatórias (180h) mais duas (120h) dentre cinco optativas contemplarão os objetivos de uma Formação Geral conforme descrito nas diretrizes para os compartilhamentos e com a 
pretensão de "imprimir" a marca "Univates" nos egressos desta Instituição? b) Embora tenham sido definidas algumas diretrizes, questiona-se como se chegou à definição final das disciplinas elencadas e respectivas ementas e bibliografias? c) Como, metodologicamente, as disciplinas serão desenvolvidas para que o objetivo de agregar um diferencial formativo aos egressos da Univates, de fato, seja atingido? Assim s pode seguir elencando mais uma série de questionamentos para os quais, em grande parte, hoje, há apenas perspectivas do que se pretende alcançar. Por isso, é importante que tanto os compartilhamentos, quanto a definição de disciplinas de Formação Geral, de Formação por Área e as respectivas ementas e metodologias sejam futuramente avaliadas no sentido de sugerir mudanças nas ementas, na metodologia, na carga horária, ou, se for o caso, substituí-las.

A partir da definição da proposta de disciplinas de formação geral, passou-se a avaliar os possíveis impactos financeiros. Essa atividade foi desenvolvida com o auxílio dos profissionais do setor de Contabilidade da Univates. Foram realizadas simulações tomando como premissas a possibilidade de aumento do número médio de alunos por turma, bem como a possibilidade de remuneração das horas destinadas às atividades complementares.

A avaliação do impacto financeiro a partir do maior compartilhamento se mostrou complexa, pois não há como afirmar de que haverá um incremento no número médio de alunos por turma. Em sendo assim, optou-se por apresentar uma análise a partir dos custos envolvidos na oferta das disciplinas considerando a margem direta calculada com base nas premissas vigentes na Univates e em uso pela Contabilidade.

O que se pode afirmar é que a cada cinco alunos a mais em uma turma é possível incrementar a margem direta em 4 (quatro) pontos percentuais. De outro lado, se tem as atividades complementares que passam a ser remuneradas. Atualmente no conjunto de cursos da Univates aproximadamente $8000 \mathrm{~h}$ (oito mil horas) de atividades complementares a serem integralizadas pelos alunos. Há de considerar que parte destas será mantida, por força de lei, dentro da carga horária mínima dos cursos, porém ter-se-á incremento de receita.

\section{CONSIDERAÇÕES FINAIS}

Decorridos mais de cinco meses de trabalho, a comissão constituída pelos Diretores de Centro e pela Pró-reitoria de Ensino apresentou proposta para que sirva de apoio às instâncias competentes na decisão de implantar ou não um conjunto de disciplinas de formação geral comuns a todos os cursos de graduação da Univates. 
A proposta apresentada e que foi implementada:

a)Inserção, obrigatoriamente, nos cursos da Univates as disciplinas (todas com 60h) de Leitura e Produção de Texto I; Temas Contemporâneos e Filosofia e Ética, totalizando 180h (cento e oitenta horas);

b) $120 \mathrm{~h}$ (cento e vinte horas) inseridas de forma eletiva por cada um dos cursos entre as disciplinas que seguem: Psicologia Geral; Sociologia e Antropologia; Empreendedorismo; Raciocínio Lógico; Metodologia da Pesquisa; Sustentabilidade e Desenvolvimento, e Leitura e Produção de Texto II (todas com 60h).

c) As Atividades Complementares são remuneradas para além da carga horária dos cursos, exceto quando da determinação legal de que elas integrem a carga horária mínima.

d)No que tange às licenciaturas, sugere-se que primeiramente se faça a inclusão das disciplinas de formação geral para tão somente em um segundo momento avançar no maior compartilhamento das disciplinas de formação de professores adotando as disciplinas acima arroladas.

Acredita-se que a pesquisa atendeu aos objetivos propostos confirmando que a adoção de disciplinas compartilhadas contribui para a sustentabilidade dos cursos.

\section{BIBLIOGRAFIA}

ALMEIDA, Edson Pacheco de. A universidade como núcleo de inteligência estratégica. In: BRAGA, Ryon; MONTEIRO, Carlos. Análise Setorial do Ensino Superior Privado. São Paulo: Hoper, 2005.

BRASIL. Plano Nacional de Educação - 2000. Disponível em:

<portal.mec.gov.br/arquivos/pdf/pne.pdf>. Acesso em: 18 out. 2010.

BRASIL. Lei $\mathbf{n}^{0}$ 9.394, de 20 de dezembro de 1996. Estabelece as diretrizes e bases da educação nacional. Diário Oficial da União, Brasília, DF, 23 dez.1996. Secção 1, p. 27839.

BRASIL. Parecer CNE/CES 776, de 03 de dezembro de 1997. Orientação para as diretrizes curriculares dos cursos de graduação. Disponível em:

<portal.mec.gov.br/cne/arquivos/pdf/CES0776.pdf>. Acesso em: 18 out. 2010.

BRASIL. Parecer CNE/CES 583, de 04 de abril de 2001. Orientação para as diretrizes curriculares dos cursos de graduação. Disponível em:

<portal.mec.gov.br/cne/arquivos/pdf/CES0583.pdf>. Acesso em: 18 out. 2010.

CENTRO UNIVERSITÁRIO UNIVATES. Projeto Pedagógico Institucional. Lajeado, RS, 2006. Documento elaborado pela Instituição.

CENTRO UNIVERSITÁRIO UNIVATES. Plano de Desenvolvimento Institucional. Lajeado, RS, 2009. Documento elaborado pela Instituição. 
CENTRO UNIVERSITÁRIO UNIVATES. Estatuto do Centro Universitário UNIVATES. Lajeado, RS, 2004. Documento elaborado pela Instituição.

CONFERÊNCIA NACIONAL DE EDUCAÇÃO. Documento final CONAE 2010: construindo o sistema nacional articulado. O plano nacional de educação, diretrizes e estratégias de ação, 2010.

FÓRUM DE PRÓ-REITORES DE GRADUAÇÃO DAS UNIVERSIDADES BRASILEIRAS. Política Nacional de Graduação. Manaus, 2004.

FRAUNCHES, Celso da Costa. Diretrizes curriculares para os cursos de graduação. Brasília: ABMES, 2008.

MARQUES, Teresa. Na medida certa. Revista Ensino Superior. São Paulo, ano 8, n. 87, 2005.

MORIN, Edgar. A cabeça bem feita: repensar a reforma, reformar o pensamento. Rio de Janeiro: Bertrand Brasil, 2004.

MORIN, Edgar. Educar na era planetária: o pensamento complexo como método de aprendizagem no erro e na incerteza humana. São Paulo: Cortez, 2003.

MORIN, Edgar. Educação e complexidade: os sete saberes e outros ensaios. São Paulo: Cortez, 2004.

MOTA, Ronaldo. Olhando para o futuro: visões da educação brasileira para os próximos dez anos. Nota de aula.

ZABALZA, Miguel A. O ensino universitário: seu cenário e seus protagonistas. Porto Alegre: Artmed, 2004. 